IJ§ER

ISSN: 2149-5939
International Journal of Social Sciences and Education Research

Online, http://dergipark.gov.tr/ijsser

Volume: 3(2), 2017

\title{
Suriyeli mülteci ve sığınmacıların çeşitli psikolojik faktörler açısından incelenmesi: Batman örneklemi ${ }^{1}$
}

\section{An investigation of Syrian refugees and asylum seekers in terms of various psycho- logical factors: Batman sample}

\author{
Vedat Ceylan² \\ Coşkun Algan ${ }^{3}$ \\ Mehmet Yalçın 4 \\ Esra Yalçın ${ }^{5}$ \\ Ercan Akın6 \\ Samet Köse ${ }^{7}$
}

Received Date: $01 / 09$ / 2016

Accepted Date: 05 / 02 / 2017

\begin{abstract}
$\ddot{O} z$
Savaş mağduru bireylerin kendi ülkelerinden göçüp başka ülkelere mülteci olarak yaşamaya başlamalarının beraberinde başta ekonomik, sosyal ve psikolojik sorunlar olmak üzere çeşitli problemler getirdiği çeşitli araştırmalar ile ortaya konulmuştur. Bu çalışmanın amacı Suriye savaşından kaçıp Türkiye'nin Batman ilinde mülteci kampında kalan kişilerin depresyon düzeyi, psikolojik iyi oluş, benlik saygısı ve algılanan sosyal destek düzeylerini incelemek ve çeșitli sosyodemografik değişkenler ile karşılaştırmaktır. Çalışmaya Batman'da mülteci kampında kalan 38 erkek ve 45 kadın olmak üzere 83 mülteci ve sı̆̆ınmacı katılmışıtır. Kişilerin sosyodemografik bilgileri kaydedilip, psikososyal değerlendirme için Psikolojik Iyi Olma Ölçekleri Kisa Formu (PIOÖ-42), Beck Depresyon Envanteri (BDE), Rosenberg Benlik Saygısı ölçeği (RBSÖ) ve Çok Boyutlu Algılanan Sosyal Destek Ölçeğin Gözden Geçirilmiş Formu uygulandı. Sonuçlar, regresyon analizi, bağımsız örneklem t testi, korelasyon analizi, Ki kare testi kullanılarak analiz edilmiştir. Psikolojik iyi olma durumunu yordayan faktörleri bulmak için çoklu doğrusal regresyon analizi uyguland. Elde edilen sonuçlara göre psikolojik iyi olma durumunu en iyi şekilde Rosenberg Benlik Saygısı Ölçeğinin alt ölçeklerinden Insanlara Güven Duyma, depresyon ve çok boyutlu algılanan sosyal destek düzeyinin yordadı ̆̆ bulunmuştur $\left(R^{2}=0.380, F(3,72)=16,167, p<0.001\right)$. Insanlara güven duyma, sosyal destek ve depresyon değişkenleri psikolojik iyi olma durumunun önemli yordayıcılarıdır. RBSÖ alt ölçek ortalama puanları cinsiyete göre karşılaştırıldığında, kadınlar ile erkekler arasında Kendilik Kavramının Sürekliliği, İnsanlara güven duyma, Psikosomatik belirtiler, Tartıșmalara katılabilme derecesi ve Anne-Baba ilgisi alt ölçeklerinin ortalama puanları arasındaki fark istatistiksel yönden anlamlı bulunmuştur. Kızlarda erkeklere göre kendilik kavramının sürekliliği, psikosomatik belirtiler ve ana baba ilgisi fazla; insanlara güven duyma ve tartışmalara katılabilme derecesi azdir. Cinsiyet ile kategorik depresyon durumları arasındaki ilişkiye bakmak için Ki-Kare testi uygulanmıştır. Elde edilen sonuçlara göre erkeklerin \%55.2'sinin, kadınların ise \%40'ının klinik depresyon sınır düzeyinin üzerinde puan aldıklarl ve cinsiyet ile depresyon düzeyi arasında istatistiksel olarak anlamlı bir fark bulunmuştur ( $\left.K^{2}=10.461, s d=4, p=.033\right)$. Savaş sürecinde kişinin yaşamış olduğu korku, dehşet, çaresizlik duyguları savaş bittikten sonra azalmakla birlikte devam edebilir ve çeşitli psikolojik sorunlar ortaya çıkarabilir. Yani travma etkeni ortadan kalksa da travma sonrasinda ruhsal bozukluklar ortaya çıkabilmektedir. Bu bozukluklar içinde en sık görülenler Travma Sonrası Stres Bozukluğu (TSSB) ve depresyon olsa da başka psikolojik etkenlerin bu insanların hayatını etkilemeye devam ettiği görülmektedir.
\end{abstract}

Anahtar sözcükler: Mülteci, sığınmacı, psikolojik iyi oluş, sosyal destek, depresyon

\footnotetext{
${ }^{1}$ Bu makale, 4-6 Kasım 2016 tarihlerinde İstanbul'da düzenlenen 2. Uluslararası Sosyal Bilimler ve Eğitim Araştırmaları Konferansında poster bildirimi olarak sunulmuştur.

${ }^{2}$ Corresponding Author: Hasan Kalyoncu Üniversitesi, Psikoloji Bölümü, Gaziantep, Türkiye, vedatcyln@gmail.com

${ }^{3}$ Hasan Kalyoncu Üniversitesi, Rehberlik ve Psikolojik Ana Bilim Dalı, Gaziantep, Türkiye,

${ }^{4}$ Hasan Kalyoncu Üniversitesi, Psikoloji Bölümü, Gaziantep, Türkiye,

${ }^{5}$ Hasan Kalyoncu Üniversitesi, Uluslararası İlişsiler, Gaziantep, Türkiye,

${ }^{6}$ Hasan Kalyoncu Üniversitesi, Psikoloji Bölümü, Gaziantep, Türkiye,

${ }^{7}$ University of Texas Medical School of Houston, TX, USA and Center for Neurobehavioral Research on Addictions, Houston, TX, USA
} 
Ceylan, V., Algan, C., Yalçın, M., Yalçın, E., Akın, E., Köse, S. (2017). Suriyeli mülteci ve sığınmacıların çeşitli psikolojik faktörler açısından incelenmesi: Batman örneklemi. International Journal of Social Sciences and Education Research, 3(2), 595-606.

\begin{abstract}
In this study, we aimed to examine the level of depression, psychological well-being, self-esteem and perceived social support level of refugees and asylum seekers in Turkey. The study sample consisted of 83 (38 male and 45 female) refugees and asylum seekers living in a refugee camp in Batman, Turkey. Sociodemographic information of the participants was collected and Psychological Well-being Scale-Short Form, Beck Depression inventory (BDI), Rosenberg Self-esteem Scale and Multidimensional Perceived Social Support Scale- $R$ were all administered. All variables were screened for the accuracy of data entry, missing values, and homoscedasticity using SPSS version 23 for Windows. Descriptive statistics are expressed as means \pm standard deviations. Independent sample student t-test, Pearson's correlation analysis, and Chi square test were performed in statistical analysis. Multiple linear regression analysis was used to find the best predictive factors of the psychological well-being. According to the results, confidence in people subscale of Rosenberg Self-esteem Scale, depression and multidimensional perceived social support level best predicts Psychological well-being $\left(R^{2}=0.380, F(3,72)=16,167, p<0.001\right)$. Selfesteem level of male participants was significantly higher than female participants. Another important result of present study revealed that $55.2 \%$ of men and $40 \%$ of women have a severe depression level and the difference between men and women in terms of depression level found to be statistically significant $\left(K^{2}=10.461, S D=4\right.$, $p=0.033)$. Following wars, although feelings of fear, despair, and helplessness decrease, they may still effect lives of some people. In other words, trauma factor disappears after a certain time, but experiences might still cause to psychological distress and disorders. Meanwhile, significant effects of confidence in people, self-esteem and social support level are present on psychological well-being.
\end{abstract}

Keywords: Refugees, asylum seekers, trauma, depression, psychological well-being

\title{
1. Giriș
}

İnsanlık tarihi boyunca insanlar çeşitli nedenler ile göç etmiştir. Daha güvenli yaşam alanları bulabilmek, daha iyi hayat koşullarına sahip olmak, yaşadığı coğrafyada karşılaştığı baskı, işkence, zulüm ve şiddetten kaçabilmek bu nedenlerdendir. Bazen de insanlar kuraklık, kıtlık, doğal afetler ve savaşlar nedeniyle zorunlu göç etmek zorunda kalmışlardır (Barnes, 2001; Gün, 2006). Zorunlu göç türü olarak ele alınan sığınma hareketleri de insanlık tarihi boyunca görülmüştür (Buz, 2004).

Birleşmiş Milletler Mülteciler Yüksek Komiserliği raporuna (UNHCR, 2015) göre dakikada ortalama 24 kişi evini terk etmek zorunda kalıyor. Bu verilere göre dünya genelinde mülteci konumuna düşen ve sığınma arayan kişilerin sayısı 65.3 milyona erişmiştir. Savaşlar nedeniyle bu sayı hızla artmaktadır. Özellikle son dönemde Orta Doğu coğrafyasındaki savaşlar ve katliamlar nedeniyle milyonlarca insan ülkelerini terk etmek zorunda kalmışlar ve mülteci ya da sığınmacı konumuna düşmüşlerdir. Bu insanlar özellikle komşu ülkelere ve gelişmekte olan ülkelere göç etmektedirler. Suriye savaşı ile birlikte 4.809 .787 insan ülkesini terk etmiştir. Türkiye'nin coğrafi konumu, geçiş ülkesi olması ve gelişmekte olan bir ülke olması nedeniyle resmi rakamlara göre 2.764.500 kişi Türkiye'ye geçiş yapmış ve burada geçici koruma hakkıyla kamplarda yaşamaktadirlar (UNHCR, 2015).

Kişilerin yaşadıkları bölgeleri, evlerini, ülkelerini terk etmesi ve yeni bir yere yerleşmeleri ile birlikte bireyler uyum güçlükleri yaşamaktadır. Yaşanan bu süreçler stres yaratıcı ve zorlayıcı nitelikte bir hayat olayıdır ve mültecilerde ve sığınmacılarda özellikle ruh sağlığı problemlerinin ortaya çıkmasına yol açmaktadır (Ehntholt ve Yule 2006). Sı ğınmacı ve mültecilerde ruh sağlığını olumsuz etkileyen risk etmenlerini göç öncesi, göç sırası ve göç sonrası diye incelenebilir. Göç öncesi dönemdeki ruhsal ve fiziksel şiddet, işkence, katliamlar, aile bireylerinden birisinin ölümüne ve yaralanmasına tanıklık etme, yıkım, yağma, çocuk kaçırma, maddi olanaksızlıklar ve travmalar ruhsal problem riskini artıran durumlardandır. Sığınmacı ve mültecilerin, göç sonrasında da ayrımcılık, temel ihtiyaçlardan mahrumiyet, yasal engeller, evsizlik, gelecek kaygısı, dil 
Ceylan, V., Algan, C., Yalçın, M., Yalçın, E., Akın, E., Köse, S. (2017). An Investigation of Syrian Refugees and Asylum Seekers in Terms of Various Psychological Factors: Batman Sample. International Journal of Social Sciences and Education Research, 3(2), 595-606.

ve kültürel sorunlarla karşılaşması ruhsal problemler yönünden risk oluşturmaktadır (Craig, Jajua, Warfa, 2009).

Bu çalışmada Suriye savaşından kaçıp Türkiye'nin Batman ilindeki kampta kalan bireylerin depresyon, psikolojik iyi oluş, benlik saygısı ve algılanan sosyal destek düzeyini incelemek ve çeşitli sosyodemografik değişkenler ile karşılaştırılması amaçlanmıştır.

\section{Yöntem}

Çalışmaya Batman'da kampta kalan 38 erkek ve 45 kadın olmak üzere 83 mülteci ve sığınmacı katılmıştır. Kişilerin demografik bilgileri kaydedilip, psikososyal değerlendirme için Psikolojik İyi Olma Ölçekleri Kısa Formu (PİOÖ-42), Beck Depresyon Ölçeği (BDÖ), Rosenberg Benlik Saygısı ölçeği (RBSÖ) ve Çok Boyutlu Algılanan Sosyal Destek Ölçeğin Gözden Geçirilmiş Formu uygulandi.

Tablo 1. Sosyo-demografik bilgiler

\begin{tabular}{|c|c|c|}
\hline & $n$ & $\%$ \\
\hline \multicolumn{3}{|l|}{ Cinsiyet } \\
\hline Kadın & 45 & 54.2 \\
\hline Erkek & 38 & 45.8 \\
\hline \multicolumn{3}{|l|}{ Medeni Durum } \\
\hline Evli & 34 & 41.0 \\
\hline Bekar & 46 & 55.4 \\
\hline Boşanmış & 3 & 3.6 \\
\hline \multicolumn{3}{|l|}{ Gelir (Aylık) } \\
\hline $0-500 \mathrm{TL}$ & 39 & 47.0 \\
\hline $500-1000 \mathrm{TL}$ & 35 & 42.2 \\
\hline $1000-3000 \mathrm{TL}$ & 9 & 10.8 \\
\hline \multicolumn{3}{|l|}{ Eğitim Durumu } \\
\hline Okur-Yazar Değil & 2 & 2.4 \\
\hline Okur Yazar & 9 & 10.8 \\
\hline İlkokul Mezunu & 10 & 12.0 \\
\hline Ortaokul Mezunu & 21 & 25.3 \\
\hline Lise Mezunu & 26 & 31.3 \\
\hline Üniversite Mezunu & 14 & 16.9 \\
\hline Lisansüstü & 1 & 1.2 \\
\hline \multicolumn{3}{|l|}{ Savaşa Tanıklık } \\
\hline Hayır & 25 & 30.1 \\
\hline Evet & 58 & 69.9 \\
\hline \multicolumn{3}{|c|}{ Bir Tanıdığını Kaybetme } \\
\hline Hayır & 37 & 44.6 \\
\hline Evet & 46 & 55.4 \\
\hline \multicolumn{3}{|l|}{ Türkiye'de Yaşama } \\
\hline Geçici & 74 & 89.2 \\
\hline Kalıcı & 9 & 10.8 \\
\hline
\end{tabular}

\subsection{Veri toplama araçları}

\subsubsection{Psikolojik İyi Olma Ölçekleri kısa formu (PIOÖ-42)}

Psikolojik iyi olma ölçekleri (PİOÖ), Ryff (1989) tarafından geliştirilmiştir. Ölçek altı boyutlu psikolojik iyi olma modeli temel alınarak geliştirilmiştir. Her biri 14'er sorudan oluşan toplam 6 boyut ve 84 sorudan oluşan 6’lı likert tipi bir öz bildirim ölçeğidir. Bu ölçme aracı, psikolojik iyi olma yapısının özelliklerini yani psikolojik iyi oluşu ölçmektedir. PİÖ’nin her bir alt boyutu 
Ceylan, V., Algan, C., Yalçın, M., Yalçın, E., Akın, E., Köse, S. (2017). Suriyeli mülteci ve sığınmacıların çeşitli psikolojik faktörler açısından incelenmesi: Batman örneklemi. International Journal of Social Sciences and Education Research, 3(2), 595-606.

için iç tutarlılık güvenilirlik katsayılarını (Chronbach alfa); özerklik için 0.86, çevre hâkimiyeti için 0.90 , kişisel gelişim 0.87 , olumlu ilişkiler için 0.91 , yaşam amacı için 0.90 ve kendini kabul için 0.93 olarak bulunmuştur(Ryff, 1989). Bu çalışmada ölçeğin 42 maddelik kısa formu kullanılmıştır. Türkçe geçerlik güvenirlik çalışması Akın ve ark. (2012) tarafından yapılmıştır. Ölçeğin Cronbach alfa iç tutarlık katsayısı 0.87 olarak hesaplanmıştır (Akın ve ark. 2012).

\subsubsection{Beck Depresyon Envanteri (BDE)}

Depresyonda görülen vejetatif, duygusal, bilişsel ve motivasyonel alanlarda ortaya çıkan belirtileri ölçmek için Beck (1961) tarafından geliştirilen 21 maddelik ölçektir. Üniversite öğrencileri üzerinde yapılan çalışmalarda ölçeğin güvenirlik katsayıları 0.60 ile 0.87 arasında bulunmuştur (Meites ve ark., 1980). Ülkemizde Türkçe geçerlik ve güvenirlik çalışmaları Hisli (1988) tarafından yapılmıştır. Hisli’nin (1989) üniversite öğrencileri üzerinde yaptı̆̆ çalışmada ölçeğin iki yarım güvenirliği 0.74 bulunmuştur.Envanterin puanlanmasında, her soruda en düşük puan 0 , en yüksek puan 3 'tür. Elde edilen toplam puan şu şekilde değerlendirilir: 0-9 puan arası, minimal düzeyde depresif belirtiler; 10-16 puan arası, hafif düzeyde depresif belirtiler; 17-29 puan aras1, orta düzeyde depresif belirtiler, 30-63 puan arası, şiddetli düzeyde depresif belirtiler (Hisli, 1988).

\subsubsection{Rosenberg Benlik Saygısı Ölçeği (RBSÖ)}

Morris Rosenberg (1965) tarafından geliştirilmiş olan ve 63 maddeden oluşan ölçeğin 12 alt ölçeği vardır. Ölçeğin orijinalinde Cronbach'ın alfa katsayısı 0,77 ile 0,88 arasında değişmektedir. Ölçeğin ülkemizdeki geçerlik ve güvenirlik çalışması Çuhadaroğlu (1986) tarafından yapılmıştır. Ölçeğin güvenirlik çalışmasında alt ölçekler için elde edilen güvenirlik katsayılarının 0.46 ile 0.89 arasında değiştiği görülmüştür. Bu ölçeğe göre 0-1 puan alanların yüksek, 2-4 puan alanların orta 4-6 puan alanların düşük belik saygısına sahip oldukları kabul edilmektedir (Çuhadaroğlu, 1986).

\subsection{4. Çok boyutlu algılanan sosyal destek ölçeğin gözden geçirilmiş formu}

MSPSS 12 maddeden oluşan ve Zimet ve ark. (1988) tarafindan geliştirilen bir ölçektir. Çok Boyutlu Algılanan Sosyal Destek Ölçeği 3 farklı kaynaktan (aile,arkadaş,özel insan) alınan sosyal desteğin yeterliliğini öznel olarak değerlendiren bir ölçektir (Zimet ve ark. 1988). Ölçekten elde edilen puanın yüksek olması algılanan sosyal desteğin yüksek olduğunu ifade etmektedir. Ölçeğin ülkemizde geçerlik ve güvenirlik çalışmaları Eker, Arkar ve Yaldız (2001) tarafından yapılmıştır. Yapılan bu çalışmada her üç farklı örneklem için Cronbach alfa katsayısı 0.80 ile 0.95 arasında çıkmıştır.

\section{Bulgular}

\subsection{Psikolojik iyi oluş açısından cinsiyet farklılıkları}

Kadın ve erkeklerin psikolojik iyi oluş, benlik saygısı, depresyon düzeyi ve algılanan sosyal destek puanlarını karşılaştırmak için yapılan bağımsız gruplar t testi sonrasında benlik saygısı, algılanan sosyal destek ve depresyon düzeyi cinsiyete göre anlamlı bir farklılık göstermez iken psikolojik iyi oluş düzeyi cinsiyetler arasında istatistiksel olarak anlamlı bir şekilde farklılık gös- 
Ceylan, V., Algan, C., Yalçın, M., Yalçın, E., Akın, E., Köse, S. (2017). An Investigation of Syrian Refugees and Asylum Seekers in Terms of Various Psychological Factors: Batman Sample. International Journal of Social Sciences and Education Research, 3(2), 595-606.

termekteydi $\left(\mathrm{t}_{0.01: 81}=0.905\right)$. Elde edilen bulgulara göre erkek mültecilerin psikolojik iyi oluş düzeyleri $(\bar{x}=163.8158)$ kadın mültecilerin psikolojik iyi oluş düzeylerinden $(\bar{x}=150.3778)$ daha yüksekti.

Tablo 2. Kadın ve Erkeklerin Psikolojik İyi Oluş düzeylerinin karşılaştırılması

\begin{tabular}{|c|c|c|c|c|c|c|c|}
\hline & Grup & $\mathrm{N}$ & $\bar{X}$ & ss & $\mathrm{t}$ & df & $\mathrm{p}$ \\
\hline \multicolumn{8}{|l|}{ Psikolojik İyi olma Düzeyi } \\
\hline & Kadın & 45 & 150.3778 & 15.62237 & & & \\
\hline & Erkek & 38 & 163.8158 & 15.62237 & 3.747 & 81 & 0.000 \\
\hline \multicolumn{8}{|l|}{ Rosenberg Benlik Saygısı } \\
\hline \multirow{4}{*}{$\begin{array}{l}\text { Kendilik Kavramının Sürek- } \\
\text { liliği } \\
\text { İnsanlara Güven Duyma }\end{array}$} & Kadın & 45 & 3.0526 & 1.06409 & 5.058 & 81 & 0.000 \\
\hline & Erkek & 38 & 1.8889 & 1.02740 & & & \\
\hline & Kadın & 45 & 1.0789 & 0.85049 & -11.966 & 81 & 0.000 \\
\hline & Erkek & 38 & 3.1778 & 0.74739 & & & \\
\hline \multirow[t]{2}{*}{ Psikosomatik Belirtiler } & Kadın & 45 & 4.5789 & 2.17643 & -5.329 & 81 & 0.000 \\
\hline & Erkek & 38 & 6.6000 & 1.21356 & & & \\
\hline \multirow[t]{2}{*}{ Tartışmalara Katılma } & Kadın & 45 & 0.6842 & 0.52532 & 5.733 & 81 & 0.000 \\
\hline & Erkek & 38 & 0.1333 & 0.34378 & & & \\
\hline \multirow[t]{2}{*}{ Anne Baba İlgisi } & Kadın & 45 & 3.5263 & 1.76661 & 2.627 & 81 & 0.010 \\
\hline & Erkek & 38 & 2.7111 & 1.01404 & & & \\
\hline
\end{tabular}

RBSÖ alt ölçek ortalama puanları cinsiyete göre karşılaştıııldığında, kadınlar ile erkekler arasında Kendilik Kavramının Sürekliliği $\left(\mathrm{t}_{0.01: 81}=5.058\right)$, İnsanlara güven duyma $\left(\mathrm{t}_{0.01: 81}=-11.966\right)$, Psikosomatik belirtiler $\left(\mathrm{t}_{0.01: 81}=-5.329\right)$, Tartışmalara katılabilme derecesi $\left(\mathrm{t}_{0.01: 81}=5.733\right)$ ve Anne-Baba ilgisi $\left(\mathrm{t}_{0.05: 81}=2.627\right)$ alt ölçeklerinin ortalama puanları arasındaki fark istatistiksel yönden anlamlı bulunmuştur. Erkeklerde kadınlara göre göre kendilik kavramının sürekliliği ( $\bar{X}$ Erkek $\left.=3.0526, \mathrm{~S}_{\text {Erkek }}=1.06409 ; \bar{X}_{\text {kadın }}=1.8889, \mathrm{~S}_{\text {Kadın }}=1.02740\right)$, tartışmalara katılma düzeyi $(\bar{X}$ Erkek $\left.=0.6842, \mathrm{~S}_{\text {Erkek }}=0.52532 ; \bar{X}_{\text {kadn }}=0.1333, \mathrm{~S}_{\text {Kadin }}=0.34378\right)$ ve ana baba ilgisi $\left(\bar{X}_{\text {Erkek }}=\right.$ $\left.3.5263, \mathrm{~S}_{\text {Erkek }}=1.76661 ; \bar{X}_{\text {kadin }}=2.7111, \mathrm{~S}_{\text {Kadnn }}=1.01404\right)$ fazla; insanlara güven duyma $\left(\bar{X}_{\text {Erkek }}\right.$ $\left.=1.0789, \mathrm{~S}_{\text {Erkek }}=0.85049 ; \bar{X}_{\text {kadın }}=3.1778, \mathrm{~S}_{\text {Kadın }}=0.74739\right)$ ve psikosomatik belirtiler gösterme $\left(\bar{X}_{\text {Erkek }}=4.5789, \mathrm{~S}_{\text {Erkek }}=2.17643 ; \bar{X}_{\text {kadın }}=6.6000, \mathrm{~S}_{\text {Kadın }}=1.21356\right)$ düzeyi ise daha düşük bulunmuştur. Bağımsız gruplar T testi sonuçları tablo 2'de verilmiştir.

\subsection{Depresyon düzeyinde cinsiyet farklıllkları}

Cinsiyet ile kategorik depresyon durumları arasındaki ilişkiye bakmak için Ki-Kare testi uygulanmıştır. Elde edilen sonuçlara göre erkeklerin \%55.2'sinin, kadınların ise \%40'ının klinik depresyon sınır düzeyinin üzerinde puan aldıkları ve cinsiyet ile depresyon düzeyi arasında istatistiksel olarak anlamlı bir fark bulunmuştur $\left(\mathrm{K}^{2}=10.461, \mathrm{sd}=4, \mathrm{p}=0.033\right)$ (Grafik 1). 
Ceylan, V., Algan, C., Yalçın, M., Yalçın, E., Akın, E., Köse, S. (2017). Suriyeli mülteci ve sığınmacıların çeşitli psikolojik faktörler açısından incelenmesi: Batman örneklemi. International Journal of Social Sciences and Education Research, 3(2), 595-606.

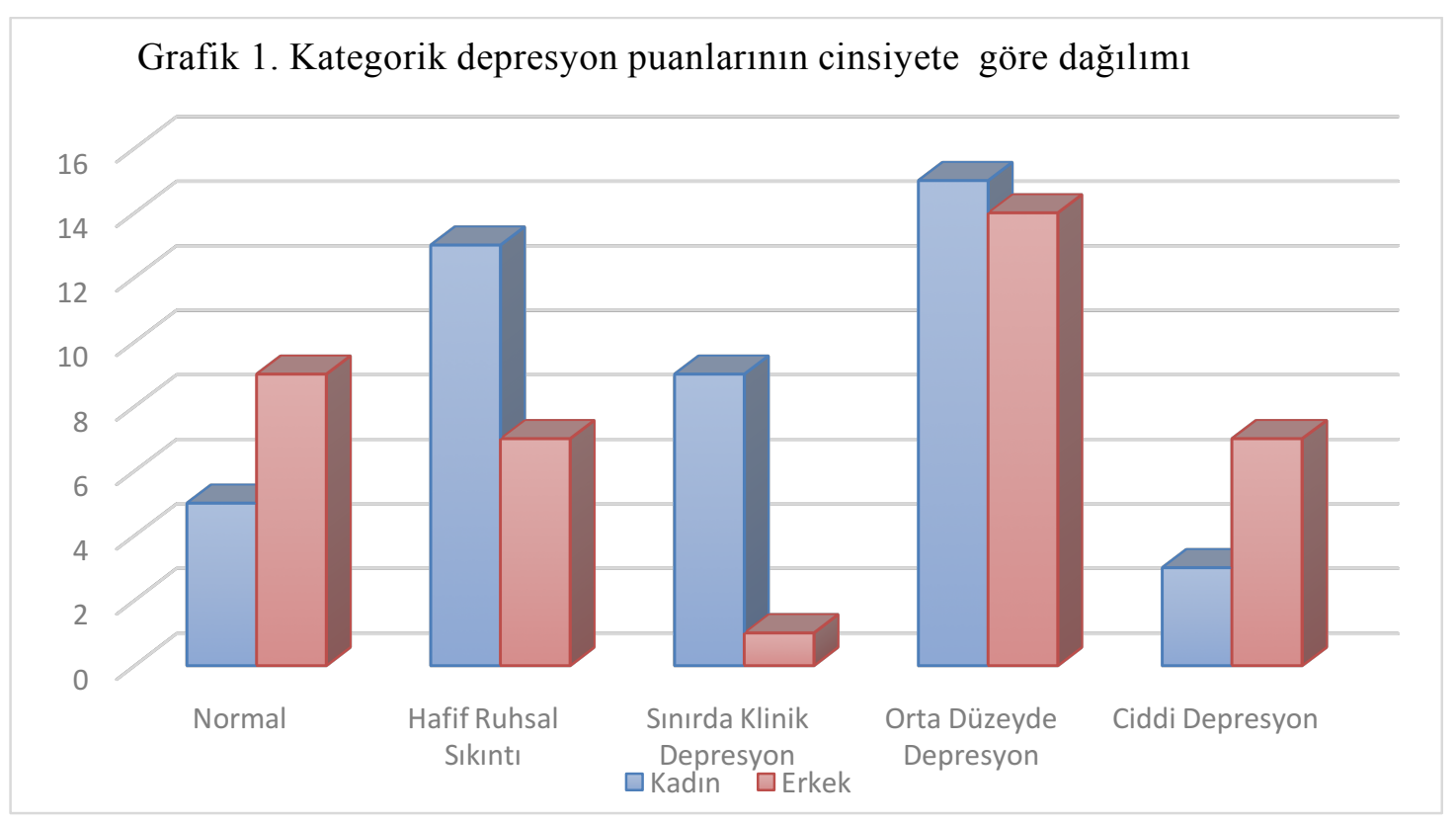

\subsection{Psikolojik iyi olma durumunu yordayan faktörler}

Psikolojik iyi olma durumunu yordayan faktörleri bulmak için çoklu doğrusal regresyon analizi uygulandı. Bulguya ilişkin analiz tablo 3'te gösterilmiştir. Elde edilen sonuçlara göre psikolojik iyi olma durumunu en iyi şekilde Rosenberg Benlik Saygısı Ölçeğinin alt ölçeklerinden İnsanlara Güven Duyma, depresyon ve çok boyutlu algılanan sosyal destek düzeyinin yordadığı bulunmuştur $\left(\mathrm{R}^{2}=0.380, \mathrm{~F}(3,72)=16.167, \mathrm{p}<0.001\right)$. İnsanlara güven duyma, Sosyal destek ve depresyon değişkenleri psikolojik iyi olma durumunun önemli yordayıcılarıdır.

Tablo 3. Psikolojik İyi Olma durumunu yordayan faktörler

\begin{tabular}{lccc}
\hline Değişken & B & SH & $\beta$ \\
Sabit & 217.004 & 9.81 & \\
& & & \\
İnsanlara Güven Duyma & -6.369 & 1.20 & $-0.48^{*}$ \\
Toplam Depresyon Puanı & -0.516 & 0.17 & $-0.27^{*}$ \\
Algılanan Çok Boyutlu Sosyal Destek & -0.642 & 0.14 & $-0.40^{*}$ \\
& & & \\
\hline $\mathrm{R}^{2}$ & & & 0.380 \\
$\mathrm{~F}^{2}$ & & & $16.167^{*}$ \\
$\mathrm{P}<0.001$ & & \\
\hline
\end{tabular}

\section{Tartıșma}

Araştırma kapsamında, Suriye Savaşından kaçıp Türkiye'nin Batman ilindeki kampta kalan bireylerin depresyon, psikolojik iyi oluş, benlik saygısı ve algılanan sosyal destek düzeyleri incelenmiştir. Yürütülen analizler sonucunda kadın ve erkeklerin benlik saygısı, algılanan sosyal destek ve depresyon düzeyi cinsiyete göre anlamlı bir farklılık göstermez iken psikolojik iyi oluş düzeyi cinsiyetler arasında istatistiksel olarak anlamlı bir şekilde farklılık göstermekteydi. Erkek 
Ceylan, V., Algan, C., Yalçın, M., Yalçın, E., Akın, E., Köse, S. (2017). An Investigation of Syrian Refugees and Asylum Seekers in Terms of Various Psychological Factors: Batman Sample. International Journal of Social Sciences and Education Research, 3(2), 595-606.

mültecilerin psikolojik iyi oluş düzeyleri kadın mültecilerin psikolojik iyi oluş düzeylerinden daha yüksek bulunmuştur. Mülteci olmaya dair yaşanan sorunların risk grubunda bulunan bireylerin daha fazla etkilendiği ve risk grubu içerisinde çocuklar, yaşlılar, gençler ve kadınların olduğu belirtilmektedir (Aroian, 1990; Ete, 1998). Ülkemizde yapılan çeşitli araştırmalarda psikolojik bozuklukların kadınlarda erkeklere oranla daha yaygın olduğu, çeşitli hastalık prevelanslarının yüksek olduğu belirtilmiştir (Bhugra, 2004; İbrikçi, 1996; Öztek ve Bertan,1982). Göçe bağlı olarak girdikleri çevrelerdeki farklı yaşam biçimleri kadınlarda psikolojik sorunları daha belirgin hale getirebilmektedir. Göç edilen ülkedeki değerlerin farklı olması uyum güçlükleri yaratmakta, bu güçlükler zamanla aile içi ilişkileri etkilemekte ve ruhsal sorunları tetikleyebilmektedir (Bhugra, 2004). Gündoğan (2015) Türkiye'ye sığınan mültecilerin kısa semptom envanterinin alt boyut puanları ve cinsiyet değişkeni açısından karşılaştırdığı bir çalışmada ise tüm alt ölçeklerde (anksiyete, depresyon, somatizasyon, hostilite, olumsuz benlik) kadınların erkeklerden yüksek puan aldığı, fakat değişkenler arasındaki farkın anlamlı olmadığını bulmuştur.

Bu araştırmada erkeklerin \%55.2'sinin, kadınların ise \%40'ının klinik depresyon sınır düzeyinin üzerinde puan aldıkları ve cinsiyet ile depresyon düzeyi arasında istatistiksel olarak anlamlı bir fark bulunmuştur. Bastin vd. (2013) tarafından Lübnan'daki Beyrut'taki bir mülteci kampında yapılan araştırmada, 1144 psikiyatri hastasının \% 28.8'inde birincil tanı olarak depresif bir bozukluk olduğu bildirilmiştir. Lindert (2009) tarafından yapılan sistematik bir inceleme çalışmasında, 24051 mültecide depresyon için \% 44'lük bir yaygınlık prevalansı bildirilmiştir. Cinsiyete göre depresyon düzeylerinin karşılaştırıldığı araştırmalara bakıldığında bizim bulgumuzun aksine kadınların depresyon düzeylerinin erkeklere oranlara daha yüksek oranlara sahip oldukları gözlemlenmiştir (Salman \& Tuna, 2002 ).

RBSÖ alt ölçek ortalama puanları cinsiyete göre karşılaştırıldığında, Erkeklerde kadınlara göre kendilik kavramının sürekliliği, tartışmalara katılma düzeyi, ana baba ilgisi alt boyutlarında daha fazla puanlar aldıkları, insanlara güven duyma, psikosomatik belirtiler gösterme düzeyleri daha düşük bulunmuştur.

Psikolojik iyi olma durumunu en iyi şekilde Rosenberg Benlik Saygısı Ölçeğinin alt ölçeklerinden İnsanlara Güven Duyma, depresyon ve çok boyutlu algılanan sosyal destek düzeyinin yordadığı bulunmuştur. Savaş ve göç gibi zorlayıcı yaşam deneyimine sahip bireylerin, psikolojik olarak iyi olma durumunu korumak için kullandıkları bazı kaynaklar olabilmektedir. Sosyal destek kavramı bu etkinin başlıca kaynağı olarak gösterilmektedir (Emmelkamp, Komproe, Ommeren \& Schagen, 2002). Mültecilerin göç ettiği ülkelerde aile, komşu, akraba ve arkadaş gibi sosyal destek sistemlerini oluşturan ilişki ağlarından yoksun olması önemli sorunlardan birisidir. Mülteci ve sığınmacılar için birincil sosyal destek kaynağı aile ve yakın arkadaş çevresidir. Savaş koşulları, yerinden edilme gibi dinamikler nedeniyle bu sosyal destek yapıları zarar görmektedir (Pérez-Sales, 2012). Yapılan araştırmalarda bireylerin algıladıkları sosyal destek arttıkça, depresyon, anksiyete gibi psikolojik sorunların azaldığ bildirilmiştir (Zhang \& Goodson, 2011; Lee, Koeske \& Sales, 2004). Yapılan başka bir çalışmada ise bireylerin algıladıkları sosyal destek arttıkça depresyonun azaldığı, yaşam doyumu ve psikolojik dayanıklılığın arttığı tespit edilmiştir (Wallace, Bisconti \& Bergeman, 2001). Akgün (2016) tarafından yapılan araştırmada algılanan sosyal destek ve dayanışma ile ruhsal iyilik hali arasında ise anlamlı bir ilişki mevcuttur. Crocker vd. (1994) 'siyah, beyaz, Asya kökenli öğrencilerin psikolojik iyi oluşu ile benlik saygısı arasındaki ilişkiyi' incelediği araştırmada psikolojik iyi olma durumu ile benlik saygısı arasında yüksek oranda ilişki bulunmuştur. 
Ceylan, V., Algan, C., Yalçın, M., Yalçın, E., Akın, E., Köse, S. (2017). Suriyeli mülteci ve sığınmacıların çeşitli psikolojik faktörler açısından incelenmesi: Batman örneklemi. International Journal of Social Sciences and Education Research, 3(2), 595-606.

\section{Sonuç}

Göç sürecinin, ruh sağllğ 1 ile ilişkisini ortaya koymak ve bu ilişkinin belirleyenlerinin neler olduğunu tespit etmek amacıyla pek çok araştırma yapılmıştır (Lin vd., 1985; Savrun \& Balcıŏglu, 1998; Westermeyer, 1989). Araştırmalardan çıkan ortak sonuca göre, insanların yaşadıkları yaşam alanlarını, ülkelerini terk ederek yeni bir yere yerleşmelerinin bireyler için zorlayıcı nitelikte bir yaşam olayıdır ve bireylerde ruhsal bozukluk veya sorunlara yol açmaktadır (Teodorescu vd., 2012). Bu araştırma katılımcıların, göç sonrası süreçte düşük benlik saygısına ve yüksek depresyon düzeyine sahip oldukları, benlik saygısı ve depresyon düzeylerinin cinsiyet değişkenine göre farklılaştığı ortaya konulmuştur. Araştırmanın önemli bulgularından olan; mültecilerin insanlara güven duyma, depresyon ve çok boyutlu algılanan sosyal desteğin psikolojik iyi olma durumunu yordadığı ortaya konulmuştur.

\section{Kaynakça}

Akdeniz, E.B. (2007). Göçmen Türk kadınlarının sorunlarının odak grup görüşmesi yöntemi ile belirlenmesi ve psikoeğitimsel modele göre danışmanlık hizmeti verilmesi.(Doktora tezi). Hacettepe Üniversitesi/ Sağlık Bilimleri Enstitüsü, Ankara.

Akgün, N. (2016). Suriyeli mültecilerde ruhsal iyilik hali ve ilişkili faktörlerin değerlendirilmesi (Ph.D. dissertation). SELÇUK UNIVERSITY.

Akın, A. Demirci, İ., Yıldız, E., Gediksiz, E., \& Eroğlu, N. (2012). The Short form of the Scales of Psychological Well-being (SPWB-42): The validity and reliability of the Turkish version. Paper presented at the International Counseling and Education Conference 2012 (ICEC 2012), May, 3-5, İstanbul, Turkey.

Aroian, K.J. (1990). Model of psychological adaption to migration and resettlement, Nursing Research, 39 (1), 5-10. Doi: 10.1097/00006199-199001000-00002

Avison, W. R., \& Mcalpine, D. D. (1992). Gender Differences in Symptoms of Depression Among Adolescents. Journal of Health and Social Behavior, 33(2), 77. doi:10.2307/2137248 12.

Barnes, D.M. (2001). Mental health screening in a refugee population: A program report. Journal of Immigrant Health, 3 (3), 141-149. Doi: 10.1023/a:1011337121751

Bastin, P., Bastard, M., Rossel, L., Melgar, P., Jones, A., \& Antierens, A. (2013). Description and Predictive Factors of Individual Outcomes in a Refugee Camp Based Mental Health Intervention (Beirut, Lebanon). PLoS ONE, 8(1). doi:10.1371/journal.pone.0054107

Beck, A. T. (1961). An Inventory for Measuring Depression. Archives of General Psychiatry, 4(6), 561. Doi: 10.1001/archpsyc.1961.01710120031004

Bhugra, D. (2004). Migration and mental health. Acta Psychiatrica Sacandinavica, 109, 243-258. Doi: $10.1017 /$ cbo 9780511760990.002

Buz, S. (2004). Zorunlu çıklş zorlu kabul mültecilik. Ankara: Sığınmacılar ve

Göçmenlerle Dayanışma Derneği Yayınları.

Craig, T., Jajua, P. M., \& Warfa, N. (2009). Mental health care needs of refugees. Psychiatry, 8(9), 351354. doi:10.1016/j.mppsy.2009.06.007

Crocker, J., Luhtanen, R., Blaine, B., Broadnax, S. (1994). Collective self-esteem and psychological wellbeing among white, black and asian college students. Pers Soc Psychol Bull 20, 503-513. Doi: $10.1177 / 0146167294205007$ 
Ceylan, V., Algan, C., Yalçın, M., Yalçın, E., Akın, E., Köse, S. (2017). An Investigation of Syrian Refugees and Asylum Seekers in Terms of Various Psychological Factors: Batman Sample. International Journal of Social Sciences and Education Research, 3(2), 595-606.

Çuhadaroğlu, F.(1986). “Adölesanlarda Benlik Saygısı”, Hacettepe Üniversitesi Tıp Fak, Psikiyatri ABD Yayımlanmamış Uzmanlık Tezi, Ankara.

Ehntholt, K. A., \& Yule, W. (2006). Practitioner Review: Assessment and treatment of refugee children and adolescents who have experienced war-related trauma. Journal of Child Psychology and Psychiatry,47(12), 1197-1210. doi:10.1111/j.1469-7610.2006.01638.x

Emmelkamp, J., Komproe, I. H., Ommeren, M. V., Schagen, S. (2002). The relation between coping, social support and psychological and somatic symptoms among torture survivors in Nepal. Psychological Medicine, 32, 1465-1470. Doi: 10.1017/S0033291702006499

Ete, E. (1998). Ethnomedizinische aspekte der Interaktion mit Türkischen patienten. Hamburger Artzte Blatt, 4 (93), 119-123.

Gün, Z. (2006). Göç üzerine psikolojik çalışmalar, yöntemsel sorunlar ve çözüm

önerileri. Türk Psikoloji Bülteni, 12 (38), 27-41.

Hisli N. (1988). Beck depresyon envanterinin geçerliği üzerine bir çalışma. Psikoloji Dergisi, 6(2), 118 122.

Hisli N. (1989). Beck depresyon envanterinin üniversite öğrencileri için geçerliği, güvenirliği. Psikoloji Dergisi, 7(23), 3-13.

İbrikçi, S. (1996). Köyden kente göçün kadının psikososyal adaptasyonu üzerine etkileri. (Doktora Tezi). İstanbul Üniversitesi/ Sağlık Bilimleri Enstitüsü, İstanbul.

Kornstein, S.G. (1997). Gender differences in depression: implications for treatment. J Clin Psychiatry, $58(15), 12-8$.

Lee, J., Koeske, G. F., \& Sales, E. (2004). Social support buffering of acculturative stress: a study of mental health symptoms among Korean international students. International Journal of Intercultural Relations, 28(5), 399-414. doi:10.1016/j.ijintrel.2004.08.005

Lin, E. H., Ihle, L. J., \& Tazuma, L. (1985). Depression among vietnamese refugees in a primary care clinic. The American Journal of Medicine, 78(1), 41-44. doi:10.1016/0002-9343(85)90459-0

Lindert, J., Ehrenstein, O. S., Priebe, S., Mielck, A., \& Brähler, E. (2009). Depression and anxiety in labor migrants and refugees - A systematic review and meta-analysis. Social Science \& Medicine, 69(2), 246257. doi:10.1016/j.socscimed.2009.04.032

Llosa, A. E., Ghantous, Z., Souza, R., Forgione, F., Bastin, P., Jones, A., . . Grais, R. F. (2014). Mental disorders, disability and treatment gap in a protracted refugee setting. The British Journal of Psychiatry, 204(3), 208-213. doi:10.1192/bjp.bp.112.120535

Maier, W., Gänsicke, M., Gater, R., Rezaki, M., Tiemens, B., \& Urzúa, R. F. (1999). Gender differences in the prevalence of depression: A survey in primary care. Journal of Affective Disorders, 53(3), 241-252. doi:10.1016/s0165-0327(98)00131-1

Önen, C., Güneş, G., Türeme, A., \& Ağaç, P. (2014). Bir Mülteci Kampında Yaşayan Suriyelilerde Depresyon ve Anksiyete Durumu. Akademik Sosyal Araştırmalar Dergisi, 2(6), 223-230.

Öztek, Z., Bertan, M. (1982). Yurt dışına göç ve sağlık. H.Ü. Toplum Hekimliği Enstitüsü Yayını. 24.

Pérez-Sales P. (2012). Assessment of trauma experiences, mental health and individual and community coping resources of refugee Syrian population displaced in North Bekaa (Lebanon). France/Spain. 
Ceylan, V., Algan, C., Yalçın, M., Yalçın, E., Akın, E., Köse, S. (2017). Suriyeli mülteci ve sığınmacıların çeşitli psikolojik faktörler açısından incelenmesi: Batman örneklemi. International Journal of Social Sciences and Education Research, 3(2), 595-606.

Ryff, C. D. (1989). Happiness is everything, or is it? Explorations on the meaning of psychological wellbeing. Journal of personality and social psychology, 57(6), 1069- 1081. Doi: 10.1037//00223514.57.6.1069

Savrun, M. ve Balcığlu, İ. (1998). Sosyal ve kültürel çevre. Yeni Symposium Dergisi, 36 (3-4), 85-89.

Salman, R., Tuna, S. (2002). Handbuch Interkulturelle Suchthilfe. Giesen, .Psychosozial Verlag.

Teodorescu, D., Heir, T., Hauff, E., Wentzel-Larsen, T., \& Lien, L. (2012). Mental health problems and post-migration stress among multi-traumatized refugees attending outpatient clinics upon resettlement to Norway. Scandinavian Journal of Psychology, 53(4), 316-332. doi:10.1111/j.14679450.2012.00954.x

UNHCR. 2015d. Protecting and Supporting the Displaced in Syria, UNHCR Syria End of the Year Report 2015.

Zhang, J., \& Goodson, P. (2011). Predictors of international students' psychosocial adjustment to life in the United States: A systematic review. International Journal of Intercultural Relations, 35(2), 139-162. doi:10.1016/j.ijintrel.2010.11.011

Zimet, G. D., Dahlem, N. W., Zimet, S. G., \& Farley, G. K. (1988). The Multidimensional Scale of Perceived Social Support. Journal of Personality Assessment, 52(1), 30-41. Doi: 10.1207/s15327752jpa5201_2

Wallace, K. A., Bisconti, T. L., \& Bergeman, C. S. (2001). The Mediational Effect of Hardiness on Social Support and Optimal Outcomes in Later Life. Basic and Applied Social Psychology, 23(4), 267-276. doi: $10.1207 / 153248301753225892$

Westermeyer, J. (1989). Paranoid symptoms and disorders among 100 among refugees: a longitudinal study. Acta Psychiatrica Scandinavica, 80(1), 47-59. doi:10.1111/j.1600-0447.1989.tb01299.x

Yııdız, M., Çapar, B. (2010). Orta Öğretim Öğrencilerinde Benlik Saygısı İle Dindarlık Arasındaki İlişkinin İncelenmesi. Din bilimleri Akademik Araştırma Dergisi, 10(1), 103-131 
Ceylan, V., Algan, C., Yalçın, M., Yalçın, E., Akın, E., Köse, S. (2017). An Investigation of Syrian Refugees and Asylum Seekers in Terms of Various Psychological Factors: Batman Sample. International Journal of Social Sciences and Education Research, 3(2), 595-606.

\section{Extended abstract in English}

Objective: Throughout human history, people have migrated for various reasons, finding safer living places, having better living conditions, pressure, torture, persecution, and violence in the geography they live are some of these reasons. Sometimes people are forced to immigrate due to drought, famine, natural disasters and wars (Barnes, 2001; Gün, 2006). Asylum movements, considered as a type of forced migration, have also been seen throughout human history (Buz, 2004). According to the report of the UN High Commissioner for Refugees (UNHCR, 2015), an average of 24 people are forced to leave their homes in a minute. This report revealed that the number of people seeking asylum in the world as a refugee reached 65.3 billion. This number is rapidly increasing due to wars. Especially more recently, due to wars and massacres in the Middle East, millions of people had to leave their countries and had fallen to the position of refugees or asylum seekers. People who leave their region, homes and countries have adaptation problems with the new places they start to live or people they start to live with. These processes are stressful and challenging life events and become the cause of some important mental health problems for refugees/ asylum seekers. Risk factors affecting mental health in asylum seekers and refugees can be categorized as factors before migration, factors during migration, and factors after migration. Psychological and physical violence in the pre-migration period, torture, massacres, witnessing the death and injury of one of the family members, destruction, looting, child abduction, material incapacities and traumas are some situations that increase the risk of mental problems. Asylumseekers and refugees are also at risk after migration due to some situations as discrimination, deprivation of basic necessities, legal obstacles, homelessness, future anxiety, language, and cultural problems (Craig, Jajua, Warfa, 2009). In this study, we aimed to examine the level of depression, psychological well-being, self-esteem, and perceived social support level of Syrian refugees and asylum seekers in Turkey.

Methods: The study sample consisted of 83 (38 male and 45 female) Syrian refugees and asylum seekers living in Batman, Turkey. Sociodemographic information of the participants was collected, and Psychological Well-being Scale-Short Form, Beck Depression inventory (BDI), Rosenberg Self-esteem Scale and Multidimensional Perceived Social Support Scale-R were administered. All variables were screened for the accuracy of data entry, missing values, and homoscedasticity using SPSS version 23 for Windows. Descriptive statistics are expressed as means \pm standard deviations. Independent sample student t-test, correlation analysis, and Chi-square test were performed in statistical analysis. Multiple linear regression analysis was used to find the best predictive factors of the psychological well-being.

Results: The results of Independent samples t-test revealed that although self-esteem, perceived social support and depression level did not show any statistically significant difference in terms of gender, the level of psychological well-being was statistically significantly different between males and females $(\mathrm{t}(81)=0.905, \mathrm{p}<0.05)$. According to the results, the psychological wellbeing of male refugees $\left(\mathrm{x}^{-}=163.8158\right)$ was higher than the psychological well-being of female refugees $\left(x^{-}=150.3778\right)$. When Rosenberg Self-Esteem Scale subscales mean scores were evaluated in terms of gender, there were statistically significant differences in Continuity of Self Concept $(\mathrm{t}(81)=5.058, \mathrm{p}<0.01)$, Trust in people $(\mathrm{t}(81)=-11.966, \mathrm{p}<0.01)$, Psychosomatic symptoms $(\mathrm{t}(81)=-5.329, \mathrm{p}<0.01)$, the level of participating in discussions $(\mathrm{t}(81)=5.733, \mathrm{p}<0.01)$, parent interest $(\mathrm{t}(81)=2.627, \mathrm{p}<0.05)$ subscales between males and females scores. The results of multiple linear regression analysis revealed that confidence in people subscale of Rosenberg Self- 
Ceylan, V., Algan, C., Yalçın, M., Yalçın, E., Akın, E., Köse, S. (2017). Suriyeli mülteci ve sığınmacıların çeşitli psikolojik faktörler açısından incelenmesi: Batman örneklemi. International Journal of Social Sciences and Education Research, 3(2), 595-606.

esteem Scale, depression and multidimensional perceived social support level best predicts Psychological well-being $\left(\mathrm{R}^{2}=.380, \mathrm{~F}(3,72)=16,167, \mathrm{p}<.001\right)$. Another important result of the present study revealed that $55.2 \%$ of men and $40 \%$ of women have a severe depression level and the difference between men and women in terms of depression level found to be statistically significant $\left(\mathrm{K}^{2}=10.461, \mathrm{SD}=4, \mathrm{p}=0.033\right)$.

Discussion: In the literature, the results of studies examining the relationship between selfesteem and gender show differences. In particular, Rosenberg (1986), one of the earliest researchers on this subject, reported that there are different findings regarding the relationship between gender and self-esteem (Rosenberg, 1986). According to the results of the study conducted by Avison and Mc Alpine (1992), males have higher self-esteem than females (Avison and Mcalpine, 1992). Other studies on this subject have reported that self-esteem does not differ according to gender (Yıldız and Çapar, 2010). In this study, males had higher scores from some subscales and females had higher from some. In the present study, both men and women had higher scores in Beck Depression inventory. In the literature, the female gender is a risk factor for depression and depression is reported to be approximately two times higher in women (Kornstein, 1997; Maider et al., 1999).

Conclusion: Following the end of wars, although feelings of fear, despair and helplessness decrease, they may still affect lives of some people. In other words, trauma factor disappears after a certain time, but experiences may cause to psychological distress and disorders. Meanwhile, significant effects of confidence in people, self-esteem and social support level are present on psychological well-being. 